Arteterapia. Papeles de arteterapia y educación para inclusión social ISSN: $1886-6190$

http://dx.doi.org/10.5209/ARTE.54139

\title{
Curar las Heridas: la creación para evocar la ausencia. La memoria de la escritura. La memoria del cuerpo
}

\author{
Marián López Fernández-Cao ${ }^{1}$
}

Recibido: 16 de junio de 2016 / Aceptado: 26 de septiembre de 2016

Resumen. Esta ponencia trata de mostrar cómo un evento traumático, un asesinato en un contexto de guerra civil, puede afectar a cinco generaciones de una familia y cómo la creación y la muestra pública puede ayudar a aliviar el dolor y reestructurar la vida y la identidad.

Escrito a cinco voces, pretende mostrar, utilizando la investigación basada en las artes, cómo la escritura y la fotografía pueden ser medios de elaborar el dolor.

Palabras clave: Trauma; arte; guerra civil; investigación basada en las artes.

\section{[en] Healing Wounds: Creation to evoke absence. The memory of writing. The memory of the body}

Abstract. This paper shows how a traumatic event, a murder in a context of a civil war, could affect five generations of the same family and how Creation and public display can help to relieve pain and to restructure life and identity.

Written by five voices, it shows, using arts-based research methodology, how writing and photography can be a means of elaborating pain.

Keywords: trauma; Art; Civil war; Arts-based-research.

Sumario. 1. Elaborar el recuerdo; 1.1. El dolor de la herida. El relato imposible de los niños; 1.2. La herida; 1.3. La herida del adulto: el texto; 2 . Tomar huellas: el viaje; 3 . Huellas, sesenta años después; 4. Referencias bibliográficas.

Cómo citar: López Fernándes-Cao, M. (2016) Curar las Heridas: la creación para evocar la ausencia. La memoria de la escritura. La memoria del cuerpo, en Arteterapia. Papeles de arteterapia y educación para inclusión social 11,365-384.

$1 \quad$ Universidad Complutense de Madrid

E-mail: mariaanl@ucm.es 
"Un guerra civil no es una guerra, sino una enfermedad (donde) se lucha casi contra uno mismo" Antoine de Saint-Exupery.

Sobre el texto de mi bisabuelo, Joaquín Cao, Memorias de un padre cuyo hijo fue asesinado durante la Revolución Española, escrito en 1937, las memorias orales de mi padre, Agustín López Cao y dos días de viaje fotográfico junto con mis hijos.

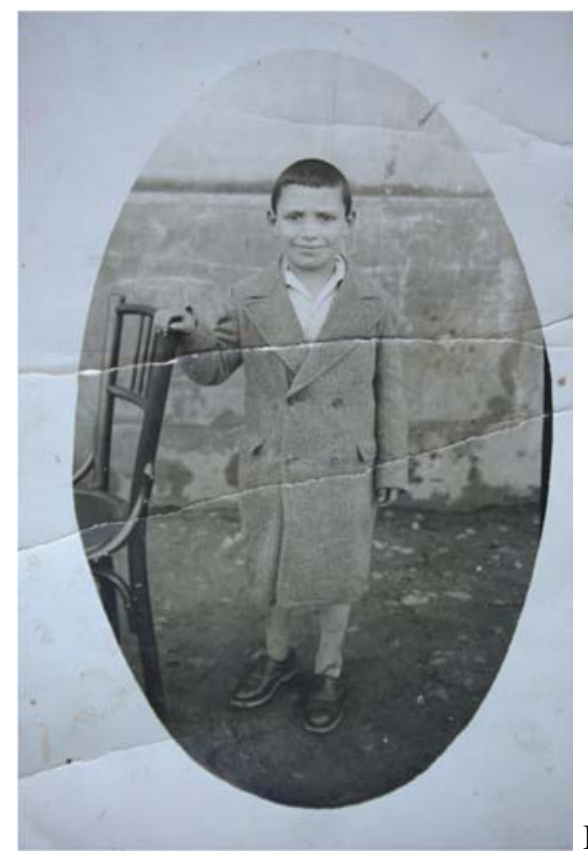

Figura 1. Autoría desconocida. [Agustín]. c. 1937.

\section{Elaborar el recuerdo}

Las experiencias de las guerras son la fuente de traumas psicológicos para aquello que luchan pero también para la población civil. La cruel represión sufrida por los perdedores en la Guerra Civil Española no sólo cerró las posibilidades de superar el trauma, sino que supuso un peso añadido a su fijación e imposibilidad de elaboración. La política del terror y silencio impuesto durante la dictadura subsiguiente a la guerra señaló las bases para una epidemia de estrés postraumático.

Muchos de los síntomas del estrés postraumático como vulnerabilidad, incapacidad de conectar hechos y eventos, el sentimiento de culpabilidad, miedo permanente, sensación de impunidad del otro no sólo no fueron tratados sino reforzados por los responsables de la dictadura. 
El evento traumático que muestro en este texto -el asesinato de una persona en la Guerra Civil- se relaciona con el trauma colectivo que fue y es todavía la Guerra Civil Española. Desde ahí, he tratado de abordar el efecto cognitivo y emocional a través de cuatro generaciones de una familia -cinco, si incluimos la generación de la persona desaparecida- y mostrar cómo el trauma transgeneracional se modula de modos diferentes en cada generación.

Esta estructura arbórea se detiene en la reflexión sobre el trauma, que contiene y da forma a los relatos personales, al igual que las formas de arte que ayudan a visibilizar el trauma colectivo y transgeneracional, que abordo paralelamente. Los relatos que constituyen la tierra de este campo por labrar, y el viaje fotográfico, el motivo para un nuevo relato, son los siguientes:

- Un manuscrito escrito dos meses después del hecho traumático, por un hombre en sus cincuenta y pocos años cuyo hijo ha sido asesinado, y a quien busca a lo largo del texto.

- Los recuerdos orales de un hombre, su nieto, que tenía nueve años cuando observa el hecho y la devastación que se convierte en un elemento que marca su vida irreversiblemente. Con ochenta años, comienza a elaborar un discurso que permite legitimar su recuerdo.

- Un viaje fotográfico, de dos días de duración, relatado por la hija, biznieta del autor del texto.

-El relato fotográfico de la última generación, que tiene la misma edad con la que su abuelo sufrió el evento catalizador del trauma.

\subsection{El dolor de la herida. El imposible relato de los niños.}

En las noches de infancia, en la paz de esas noches de sueño profundo, rítmico y continuo que sólo pertenece a los niños y que nos abandona una vez desvanecida la inocencia, nos despertaba un grito de angustia y miedo en el espacio silencioso de la casa a oscuras.

El lamento de mi padre en la noche se insertó en el devenir infantil y cotidiano de nuestras vidas. En medio del sueño, nos hacía abrir los ojos, entre atónitas y asustadas, esa voz desgarrada de un hombre aterrorizado que, sin embargo, en la vigilia, era el modelo dulce, tranquilo y sosegado, ejemplo y referencia masculina de nuestras vidas de niñas, de nuestros sueños de niñas. "Es papá, soñando con la guerra”, susurraba apenas una de mis hermanas mayores. Al momento, la voz de mi madre aliviaba el grito y nuestro silencio expectante, "Despierta, Agustín, no pasa nada, estás soñando, Agustín, estás soñando”.

El desorden de estrés postraumático (PTSD) está caracterizado por tres grupos de síntomas: reexperimentación intrusiva, evitación de recuerdos e hiperestimulación, incluida la hipervigilancia y la respuesta exagerada. Es típico de las personas que experimentan PTSD reexperimentar los eventos traumáticos en forma de episodios de flashback, pesadillas o pensamientos aterradores (Collie, K.\&Backos, A., 2006: 
157). El PTSD es causado en parte por la naturaleza de la memoria traumática, que está indexada en los sistemas de memoria implícita y declarativa a un tiempo parece estar disociada en forma de fragmentos emocionales, preceptúales y sensoriales con una base verbal no coherente, simbólica o temporal (O'Kearney \& Perrott, 2006; Reisberg \& Hertel, 2004).

Mi padre nos contaba a veces que, cuando él tenía apenas nueve años, en los albores de la guerra civil en el sureste de la provincia de Ourense, se quedó tartamudo, durante un año. Casi sin habla.

La memoria implícita y declarativa del evento puede verse desconectada por el impacto del hecho traumático. Por ello las cualidades del recuerdo traumático se hacen difíciles de describir a través de palabras, o integrarlas como parte de la historia de vida (Christianson, 1992; van der Kolk, Hostetler, Herron, \& Fisler, 1994). La dificultad de procesar la información simbólicamente (verbal o de otro modo) tras el trauma es un elemento crucial de la PTSD (van der Kolk \&

Fisler, 1995). De hecho, investigaciones sobre la imagen cerebral han demostrado hipoactividad en el área de Broca, que es la responsable de los aspectos motores del habla, e hiperactividad en la amígdala (miedo, terror), hipocampo (memoria) y corteza occipital (proceso visual) (Rauch \& Shin, 1997).

A lo largo de los años he tratado de imaginar en interminables ocasiones qué poblaban esos sueños, qué imágenes repetidas, impronunciables durante un largo año, aparecían, una y otra vez, en la mente, en el cuerpo en zozobra de mi padre. Y pocas veces me atrevía a preguntar, por el dolor renovado que pudiera producir, porque la noche se acababa y pocas veces se mencionaba lo ocurrido. La noche, como espacio donde surge lo indecible, lo insoportable. Supongo que en nosotras se coló, a través del testimonio del dolor ajeno pero próximo y del miedo intransferible de aquellos gritos, la marca de la vulnerabilidad, del sufrimiento infantil en el cuerpo de un mayor. La huella del dolor que no se va nunca, la señal que, una vez formada, siempre permanece. Creo que era una advertencia vital, que nos ha marcado a su vez, como un aviso. Muchas veces lo he querido relacionar con el sufrimiento sin reparación -el sufrimiento nunca tiene en realidad reparación-, con la herida abierta, con la pérdida primigenia, por otro lado, constante en cada ser humano. Pero algunas noches, ya adolescente, se me hacía insoportable e injusto sentir en la habitación contigua un cuerpo querido que una y otra vez, no era capaz de desasirse de un desconsuelo de niño que, cada cierto tiempo volvía, y se abría desgarrado aun cuando hubiera otro cuerpo, el de mi madre, que lo abrazara e intentara sostener su espanto.

Lo que está alterado básicamente es la memoria autobiográfica, en tanto que la memoria del trauma no se constituye como una historia coherente donde los aspectos de la experiencia están fusionados en una narrativa y de forma integrada 
en la dimensión vital e íntima del tiempo subjetivo, sino que las recolecciones del trauma se constituyen en fragmentos separados de la conciencia que no han podido ser integrados y permanecen desconectados de la historia global de la vida de la persona. Esta condición fragmentaria implica, en vez de ello, una falta de control de parte de la víctima, que confiere a los recuerdos traumáticos un carácter invasivo que continuará torturando a las víctimas durante un tiempo indefinido.

Uno de los objetivos prioritarios de la aproximación terapéutica implica que la víctima intente reconstruir lo que ha sucedido en su experiencia traumática a través de una historia coherente y organizada.

\subsection{La herida}

A pesar de que mi padre fue en su período laboral un economista organizado, metódico y educado -y un verdadero experto en la guerra civil española- no es capaz de mantener un discurso lógico, se ofusca, la emoción le impide hablar y sus relatos aparecen desconectados cuando recuerda determinados hechos. Cuando habla emocionado de las imágenes que retiene, muy raramente, recuerda la sensación de abuso general hacia las personas referente para él, recuerda la crueldad y el miedo constante y la impunidad reinante. Fue testigo de la muerte de niños, compañeros de clase y seres amados y recuerda imágenes claras, como la presencia de cadáveres en las cunetas que nadie se atrevía a recoger y enterrar. Relata la muerte de un amigo:

Lo mataron delante de mí.

El tendría trece años y yo, unos nueve.

Fue la semana del comienzo de la guerra.

Le dispararon directamente en el estómago,

... venían en camionetas negras, con el símbolo de dos tibias cruzadas, celebrando la insurrección y mi amigo levantó el puño.

Sólo eso.

Creo que si hubiera tenido algunos años más, yo hubiera hecho lo mismo... Aquí había ganado el Frente Popular ¿sabes? Todos los niños levantábamos el puño, como un juego, solíamos correr detrás de los pocos coches que aparecían... Le llevo más de dos horas morir.

Pedía constantemente agua,... tenía todos los intestinos fuera.

Un hombre del pueblo tuvo a mi amigo entre sus brazos, tratando de recoger su vientre lleno de sangre, hasta que murió.

Las memorias traumáticas pueden organizarse y reducir su carga emocional a través de una "narrativa coherente del trauma" que resitúa las memorias traumáticas en memorias declarativas que entonces pueden ser reinterpretadas e integradas en la historia de vida de una persona. Por su naturaleza, las memorias traumáticas son difíciles de expresar sólo a través de palabras (Collie, K.\&Backos, A., 2006: 162). 
Me cuenta cómo, cuando se levantaba muy temprano para ayudar a su padre a regar los huertos, no podía dejar de mirar los ojos de los muertos, abandonados en las cunetas de los caminos cada madrugada:

los muertos nos miraban e incluso cuando me insistían en que no mirase, no podía dejar de hacerlo. Nadie se atrevía a enterrarlos. Podían estar allí semanas.

Cuenta que su familia cambia radicalmente tras la muerte de su joven tío. Su abuelo se encierra durante meses en una habitación. Cuenta cómo reinaba la barbarie y la impunidad.

Ha transmitido a sus hijas, nos ha transmitido, la paradoja de la necesidad de rebelarse ante la injusticia, junto con la prevención constante hacia las personas, las instituciones, la idea de la reversibilidad y mutabilidad de las leyes y la desconfianza de los que administran la justicia.

Se siente feliz de los cambios políticos, vive con pasión cada cambio hacia la libertad pero no es capaz de involucrarse.

El filósofo, teólogo y escritor francés, Paul Ricoeur publica a mediados de los ochenta su tratado Tiempo y Narración. Apoyado sobre ideas de San Agustín y Heidegger, Ricoeur sitúa la narrativa en el centro de la conciencia humana. Propone que la narrativa es una proceso de estructuración mental a través del cual los humanos definimos nuestra relación existencial con los movimientos de la tierra y los planetas, estrellas y galaxias; con nuestra perspectiva lineal del tiempo tipificada por la invención del calendario; con hechos en los mundos objetivos y subjetivos; y con nuestra sensación de movernos desde el pasado al futuro, a través de la retrospectiva y la anticipación, con el presente como una continua interacción con ambos (Sheehan 1997; Cobley 2001: 16-21).

En los últimos tiempos, han ido a visitarle representantes de la memoria histórica de Galicia y sorprendentemente el encuentro con terceros le ha permitido relatar los hechos con una impresionante capacidad organizativa. El proceso le ha dado legitimidad y reconocimiento y se siente respetado.

Ahora se da cuenta de que aquellos recuerdos han sido transformados de relato personal en historia real. Y pueden ser contados.

Siente que, por primera vez, su voz respecto a estos recuerdos, es escuchada. Se siente respetado sobre las emociones que ha sentido durante años y ve cómo, tras décadas de silencio, sus recuerdos se han convertido en documento histórico, un documento sobre la historia de España.

Los procesos de recuperación de la memoria, sea ésta oral, escrita o a través de diversas creaciones, tiene un efecto terapéutico en las personas que la han vivido, 
sobre todo si esos individuos encuentran una comunidad oyente capaz de escuchar y validar sus experiencias.

Hoy esa comunidad comienza a escuchar a quien poco a poco comienza a su vez a sentirse legitimado para expresar la memoria traumática a través del relato, algo imposible de realizar anteriormente en la sociedad española, debido al período de cuarenta años de dictadura, que impidió la convivencia de relatos. Durante ese período, la psiquiatría oficial ofrecía una imagen de los vencidos como degenerados y subhumanos y la posibilidad de elaboración social, de simple expresion del dolor y el duelo, queda deslegitimada, interrumpida y confinada a la elaboración íntima y privada, si el sujeto tiene medios psíquicos para hacerlo. En ese contexto, no hubo lugar para curar las heridas de los traumas, las heridas más profundas de las guerras.

\subsection{La herida del adulto: el texto}

Desde 1980 James Pennebaker, psicólogo social, y sus colegas de investigación (véase, por ejemplo, Francis \& Pennebaker, 1992; Pennebaker y Beall, 1986) han estado experimentando con el vínculo emocional entre comunicación por escrito y la salud. La mayoría de los estudios se han llevado a cabo en condiciones de laboratorio, la mayoría mediante ensayos controlados aleatoriamente.

Pennebaker (1990) narra la historia de su viaje de investigación desde la inhibición como una amenaza para la salud, y de la escritura (o expresión oral) acerca de las emociones y pensamientos como una forma poderosa de "confesión".

El paradigma de Pennebaker no sólo ha sido asumido en muchas poblaciones y continentes, sino que también ha recibido una amplia acogida en los medios, con titulares como "la pluma es más poderosa que la píldora" (Bower, 1999).

Hace unos años descubrimos, gracias a internet, casualmente, la existencia del manuscrito de mi bisabuelo, Joaquín Cao, Memorias de un padre sobre un hijo que le fue asesinado durante la revolución española. Un manuscrito de veintiocho páginas, en papel apergaminado, de pequeño tamaño, poco más de una cuarta de largo por doce centímetros de alto, delicadamente cosido, y exquisitamente escrito en tinta azul. Mi prima Cristina Cao, a la cual no conocíamos, lo había conservado gracias al cuidado de su padre y abuelo. Un texto que permaneció, durante muchos años, escondido en las paredes de piedra de la casa familiar paterna.

Alfred Lange, psicólogo clínico, ha publicado una serie de estudios monográficos de trabajo con pacientes que han utilizado la escritura estructurada para la superación del trauma y los síntomas del estrés post-traumático (Lange, 1994, 1996). Neimeyer señala a la escritura como un medio para elaborar la pérdida, que puede convertirse en elemento ritual: escribir una biografía de la persona desaparecida, una apología, etc. pueden servir como elementos no solo estructurantes de los hechos, sino modos de elaborar e introyectar lo ocurrido, 
dándoles un lugar y un sentido en el presente. Los rituales narrativos que este autor propone son, entre otros, cartas que no se envían, en los cuales se intercala la narración explícita del acontecimiento con las reacciones íntimas de pensamiento y emoción que nos ha provocado (Neimeyer, 2007, en Darío Páez, Miryam Campos y Marian Bilbao, 2008, 15). De este modo, la narración de los hechos, junto con nuestras acciones y emociones (hacer, sentir, pensar) conforman un modo adecuado utilizado en muchos casos como único modo de dar sentido a lo acaecido.

El texto que conservamos de mi bisabuelo es hermoso y triste. Cuando llega a mis manos, brota de nuevo el dolor, tres generaciones después. Recuerdo leerlo entre lágrimas ante la mirada atónita de mis pequeños hijos que no entendían por qué lloraba la muerte de un ser que no conocí, acaecida hace más de setenta años. Un texto que muestra un dolor inconsolable. En él confluye la descripción de los hechos que dieron lugar al asesinato sin juicio previo, de su hijo Julio, en enero de 1937 en la frontera entre Galicia y León, a manos de miembros de la Falange, y el sentimiento desgarrado y desgarrante de la pérdida sin posibilidad de duelo. El apego, el acogimiento, el amor, el dolor ante el dolor del otro, la com-pasión, recorre el texto que busca un cuerpo vivo que proteger, cuidar y mantener. En él se destila el dolor ante el dolor posible del otro amado, ante el hecho de que éste se halle en un lugar des-habitado por él mismo, desconocido, en el que extrañarse, perderse, en definitiva, morir. La aniquilación que comienza con el extrañamiento, la incapacidad, la impotencia:

\section{"pobre hijo mío, (...) sacado de noche por un campo para ti completamente desconocido (...) atadas tus manos (...) ¿te habrán martirizado durante el vía crucis, o en el lugar del calvario?”}

Y luego, cuando no queda esperanza, cuando la esperanza de vida se derrumba: un cuerpo muerto que acoger y sepultar. La insondable ausencia en la búsqueda de un cuerpo que abrazar recorre el texto:

"Si era posible recoger su cuerpo mediante autorización competente y de no poder ser así, y ya como último recurso, por lo menos saber dónde lo habían sepultado"

\footnotetext{
"no tan solo no se conseguiría autorización, ni siquiera encontraríamos persona que nos acompañara a buscarlo por terror"

“... intentamos nuevamente averiguar el lugar o sitio donde lo habían enterrado (...) Lejos de averiguar algo, el terror había aumentado. (...) y las personas con quienes hablaron les aconsejaron que no hicieran gestión alguna encaminada a ese fin"
} 
Todos los rituales funerarios de recogida, aceptación y cierre quedan suspendidos, dramáticamente. Todos los pasos del cuidado corporal, que envuelven el último y delicado contacto con el cuerpo amado, tratando de aminorar con la última caricia el dolor de la muerte ya acaecida, se arrebatan. Se roba la última mirada sobre los rostros, sobre los cuerpos que quisimos, que queremos. Se niega el saber del otro, de su existencia, de su no-existencia. Se arrebata la capacidad de saber de la pérdida. Toda la red de la cultura que acoge la muerte se resquebraja, al encontrar la ausencia en lugar de la carne:

"...la noche en que toda la familia reunida llorando, se nos figuraba que velábamos su cuerpo, y sin embargo, éste ya hacía ya dos días que debía haber sido malenterrado, como otros muchos compañeros de infortunio, probablemente en un terreno inculto o tal vez en una tierra de labor, dicen que a unos cinco kilómetros de Ponferrada"

"La gente del pueblo, enterada de nuestra desgracia, fue entrando en nuestra casa a darnos el pésame, el cual no ofrecía duda alguna que en su mayoría era muy sincero porque le querían."

Hacer relato es un modo de resistir el silencio. Cuando los grupos marginados se unen en el relato, el decir de sus experiencias comienza a tomar forma; apelando a su autoridad como constructores de relato, articulando su propia ética desde la experiencia, pueden mostrar los quiebres de las narrativas dominantes, permitiendo así que emerja una nueva narrativa cuidadosa (Andrews 2004; Fivush 2010). Este "hablar a través del silencio" puede ser experimentado como curativo al estar conectado con la salud psíquica, sobre todo cuando lo comparamos con aquellos grupos carentes de narrativa alguna.

Como señala Paez et alii (2008), siguiendo a Fratarolli (2006), la expresión ayuda a vivenciar un episodio emocional de forma retrospectivamente controlada, reforzando la capacidad de auto-regulación emocional o auto-eficacia de control emocional. La expresión en torno a un hecho emocionalmente relevante permite habituarse a el, reducir la activación afectiva, los pensamientos repetitivos y poder aproximarse a situaciones y contextos que la hacen revivir el hecho y escribir, hablar y narrar ayudan a procesar y organizar cognitivamente las experiencias emocionales.

En el caso que nos ocupa, un adulto es capaz de construir un relato coherente, organizando la experiencia y la emoción. En contraste, un niño sobrepasado por los mismos acontecimientos, introyecta el trauma, se queda sin palabras ante un acontecimiento que quedará sin elaborar. 


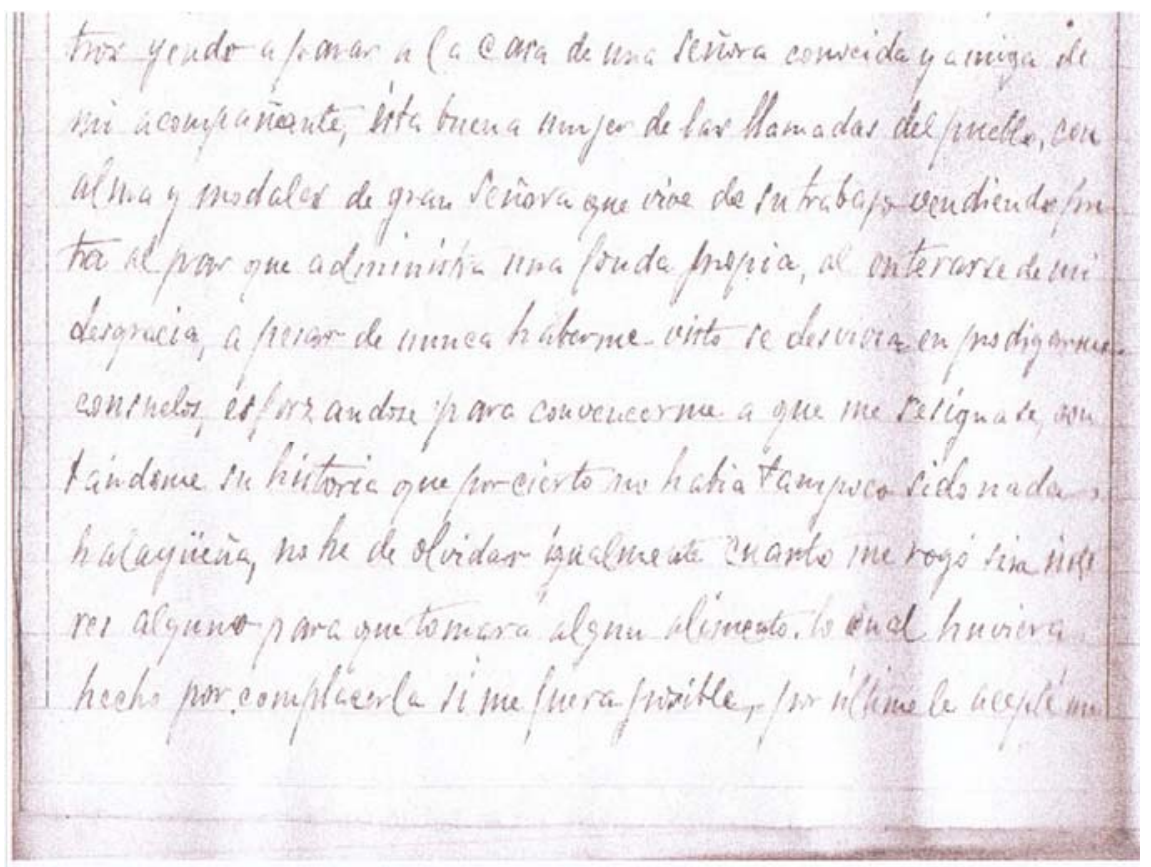

Figura 2. Memorias de un padre cuyo hijo fue asesinado durante la Revolución española.

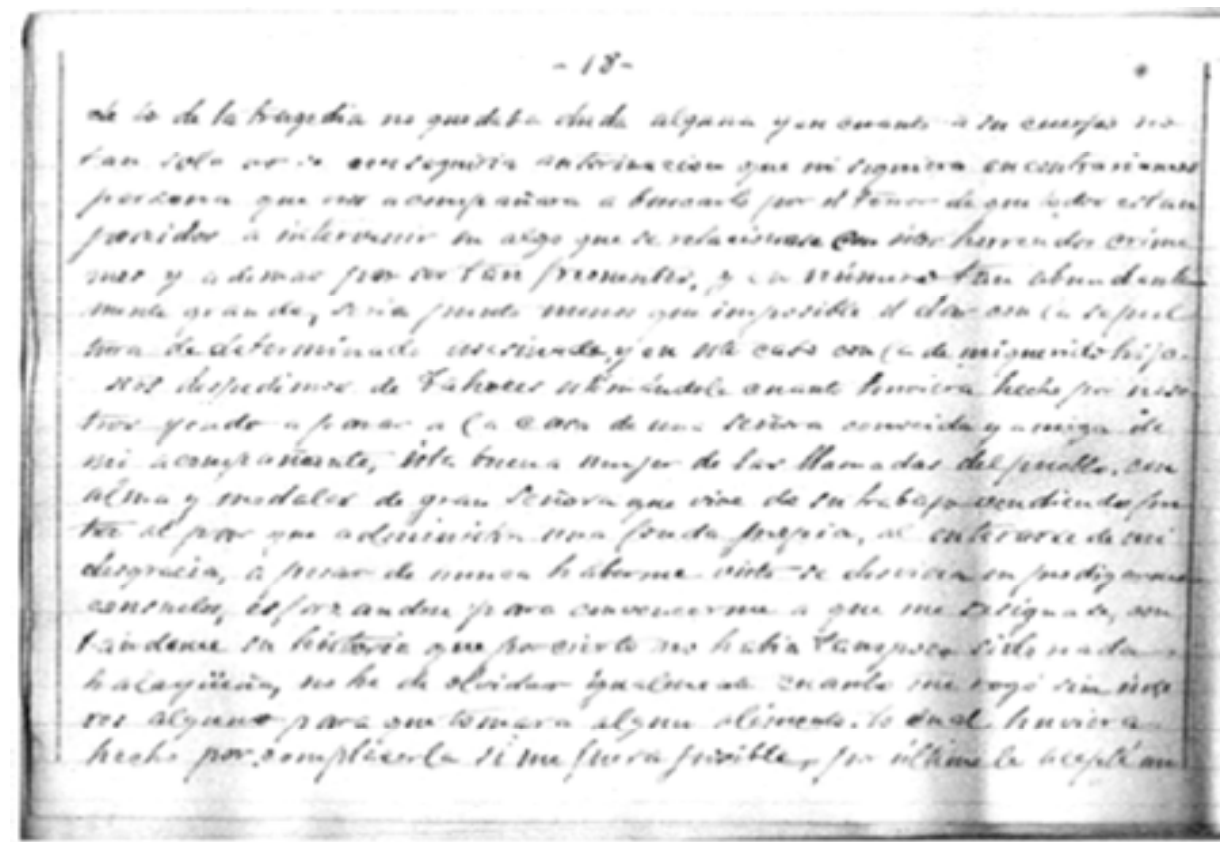

Figura 3. Memorias de un padre cuyo hijo fue asesinado durante la Revolución española, pagina 18. 
La prohibición de sepultar los cadáveres asesinados - y de saber de ellos- se convierte, a través del texto, en un hecho que mi bisabuelo relata entre el horror, la perplejidad y el desmoronamiento moral:

\section{"Un joven de la Rua, casi un niño de dieciséis años, fue muerto en el monte de su pueblo, quedando su cuerpo sobre la superficie de la tierra cerca de un mes en que por fin fueron mal sepultados sus huesos"}

“...quemados vivos en un pajar del pueblo de Cerejido (...) con igual ensañamiento procedieron con sus cuerpos no permitiendo a sus familiares recogerlos".

la escritura, como nexo entre el hueco del pasado y el presente, como necesidad de tender hilos a otras generaciones, sujetos, cuerpos haciendo la urdimbre de eso que llamamos memoria. Como intento de tejer algo con el dolor propio, de explicarse el dolor a uno mismo y hacer partícipe de este saber del dolor, al otro. De ello surge también esta escritura.

\section{Tomar huellas: el viaje}

Tras el descubrimiento del texto, que mi padre ha sido incapaz de leer, pensé en cómo devolver a mi padre, un poco de paz. Mi bisabuelo había encontrado en la escritura poética el modo de insertar, a través de un relato, una experiencia traumática. Mi padre, que había experimentado el trauma con nueve años, no había podido reponerse de los efectos de la guerra. Una huella psíquica y corporal había dejado en él un tartamudeo infantil que le había hecho enmudecer durante un año y que surgía muy de cuando en cuando, cuando se desbordaba, además de las pesadillas nocturnas que se abrían desgarradas una y otra vez conformando en él una vulnerabilidad estructural ante la impunidad de la vida.

De algún modo el texto, como un tercero, como un medio, se nos presentaba útil para reconstruir algo que había quedado roto, fragmentado y amordazado en la memoria corporal de mi padre. En julio de 2007, le propuse realizar el último viaje de su tío, desde que lo detuvieron en casa de su abuelo hasta que desaparece, a través de las memorias del bisabuelo y hacer fotografías de los lugares. Pensaba que iba a rechazar mi oferta, pero aceptó.

En el texto, mi bisabuelo va tras su hijo que ha sido encañonado, maniatado e introducido en la camioneta de la Falange, primero, y luego, pérdida la esperanza, en búsqueda de su cuerpo. Más adelante, el texto relata pormenorizadamente todo el paisaje del horror y la barbarie de la comarca de Valdeorras, donde los falagistas campan feroces matando y sembrando el miedo y el terror.

Le propuse un viaje fotográfico, donde dejáramos constancia de los lugares de detención, torturas, posible ejecución y, además, visitar todos y cada uno de los lugares que mi bisabuelo narraba en el texto. Asintió. 
El viaje tendría que haber sido realizado por mi padre y por mí: quería hacer de él un cierre, una reconciliación silenciosa, dando tiempo a la emoción, simbólica. Pero mis hijos, sus nietos, de ocho y tres años, quisieron acompañarnos. Uno de mis hijos tenía casi la misma edad que tuvo mi padre cuando los hechos acaecieron. Insistieron en la búsqueda de "Cao Cao" (así se apellidaba mi tío abuelo) con su abuelo, y no pude pensar una explicación para decirles que no. Para dar cierto sentido, propuse a mi hijo mayor que fotografiara, él también, a su abuelo, a mí misma, a los lugares. Viajábamos de repente cinco generaciones tratando de hacer, con las imágenes, un pacto con el pasado: mi bisabuelo Joaquín, a través del texto; mi tío abuelo Julio, desaparecido; mi padre, Agustín; yo, Marián; y mis hijos, Federico y Bruno. El segundo día se unió mi madre, América.

Todos unidos por un trauma familiar, pero también colectivo y transgeneracional que había calado silencioso en cada una de nuestras estructuras psíquicas.

La fotografía, como un tercero más, se nos presentaba como elemento mediador entre la realidad y nosotros, $e$ incluso entre nosotros mismos: mi padre rehusó fotografiar, pero yo me ofrecí como mediadora, intérprete fotográfica que da presencia a un recuerdo imborrable: mi padre me indicaba qué debía fotografiar, yo fotografiaba y mi hijo fotografiaba, a su vez, a mi padre y a mí. De algún modo se entrelazaron tres miradas: la de mi padre que señalaba, incapaz de hacer, de habitar de nuevo a través de la fotografía; la mía, de hija, que trataba de acompañar esa otra mirada que viajaba hacia atrás $y$, a la vez se reconocía en la extrañeza de un pasado sin cierre. Es cierta la afirmación de Susan Sontag, mirar, fotografiar, es, de algún modo, poseer. Mi padre no podía poseer un paisaje, al igual que no pudo en su momento dar sentido a un recuerdo de dolor desgarrado.

En su lugar, acompañando, yo poseía por él y le ofrecía los resultados, del mismo modo que mi hijo, seguro y feliz en la vida que le ha tocado vivir, habitaba y hacía suyo mi rostro, el de su abuelo, el de su hermano y todo el contexto que le rodeaba integrando gallinas, rostros y cerezos de dos magníficos días de verano. Al fondo, como una bruma, la memoria.

Mi padre lloró en casi todos los lugares donde nos detuvimos: en la puerta de la casa donde lo encañonaron -y donde él, niño, estaba presente-, donde lo esposaron con cuerdas, y en especial en la celda, donde torturaron a su tío, un lugar sin ventanas bajo tierra, ahora reconvertida paradójicamente, en sala de exposiciones. Mis hijos, detrás, eran el ejemplo de la nueva generación, vital, desorganizada, pero tremendamente cariñosa con su abuelo.

Las carreteras eran extremadamente sinuosas. Mi hijo pequeño vomitó justo en uno de los lugares donde recientemente habían exhumado restos de una fosa común de la guerra (los cinco de Priaranza). La combinación del recuerdo triste, el cariño y el cuidado estuvieron mezclados continuamente. Ver a mi padre con mi hijo en brazos frente a las fosas me hizo ver, encarnado, cómo el pasado permanece pero también, como la promesa de futuro tiene la capacidad de aliviar el presente apaciguando el pasado. Cómo, como señala Hannah Arendt, el perdón por el pasado y la promesa del futuro tiene que viajar con nosotros. 
En el camino a Cereixido, un lugar donde -según el texto de mi bisabuelo- fueron quemadas vivas varias personas huidas cuyos cadáveres, como práctica impuesta, se impidió recoger, en el camino digo, recogimos tanto orégano, tanto, el campo estaba tan bonito, que resultaba paradójica nuestra visita hacia al horror cuando la vida nos regalaba una tarde cálida de julio plena de olores veraniegos de montaña.

Cereixido era un pueblo casi deshabitado, con dos o tres personas. Mi padre no lo había visitado jamás. El lugar que buscábamos, el pajar, seguía intacto, quemado, desmoronado, con la vegetación que se había adueñado de parte de sus piedras desmoronadas, pero que dejaba entrever la barbarie. Todos los del pueblo conocían perfectamente la historia y nos llevaron al lugar. A la vez, mi hijo fotografiaba gallinas y se subía a los árboles a coger cerezas.

Cuando llegamos, una timidez repentina me impidió preguntar. Sentía que no tenía mucho sentido despertar un hecho terrible sucedido hace setenta años, en una tarde plácida de verano. Era como irrumpir en la existencia tranquila con fantasmas adormecidos. Pero vivos. Sin embargo mi padre, apoyado en "mi proyecto", abordó sin problemas a los vecinos, preguntándoles por el pajar, los huidos, la guerra. Fue curioso como íbamos intercambiando los papeles y cómo esa acción de mi padre, centrado e inserto en lo que íbamos a realizar, y coherente con nuestro viaje, fue capaz de centrar nuestro empeño cuando yo flojeaba en mi papel de mediadora.

Fotografiamos cunetas, pequeños espacios entre la carretera, repechos donde mi bisabuelo señalaba asesinatos y cuerpos abandonados,...

Hicimos imagen presente del texto pasado a través del entrecruzamiento de nuestras miradas tratando de aliviar, con el placer de vivir, el dolor que causa, a veces, la vida.

El viaje, de dos días, estuvo lleno de sensaciones en las que se mezclaba el pasado y el presente, la vida silenciada y la vida feliz de los más pequeños. Creo que mi padre sintió todo ello junto: la terrible pérdida y la esperanza y la sensación, en definitiva, de estar siendo, aunque fuera un poco, acompañado en sus pesadillas.

En casa, con las imágenes, fuimos dándoles forma, ordenándolas, poniéndoles nombre con mi padre al lado.

El hecho de organizar con él, ordenar, secuenciar y señalar acontecimientos, permitió ordenar algo que en la memoria de un niño, había quedado sin palabras: disperso y fragmentado en el pequeño cuerpo infantil que vivía aun en mi padre. $Y$ que gracias al relato de su abuelo, recuperaba su cualidad tangible. Un trauma que, por fin, tenía fechas, imágenes, lugares. Habíamos situado espacios de pérdida y dolor que podían, por qué no, convivir con un presente que debe enterrar a sus muertos para poder hacer las paces con el futuro.

El recuerdo, a través del positivado en papel, se organizaba y estructuraba en la mesa de casa: sucesos, aspecto, datos. Ambos los miramos, organizamos y reorganizamos, discutimos su ubicación, hasta corporeizar, a través de las 
fotografías de la comarca de Valdeorras y el Bierzo, los recuerdos que hace setenta y nueve años, enmudecieron a los niños de un país.

El viaje conjunto, con mis hijos, mi padre, mi madre, y aquellos que no están y quedaron, se convirtió en una experiencia que ha dado como resultado compartir un dolor preciso y situado, incardinado en un relato que, de generación en generación, ha recorrido de modo diverso nuestras diferentes vidas y ha dejado una huella indeleble en nuestros cuerpos.

La creación crea significado, crea sentido. Busca, en los lugares recónditos del inconsciente, material de trabajo. Es este material el que, organizado a través de la creación, nos permite dar sentido. El valor de toda actividad creativa no recae simplemente en la libertad de expresión, sino en la oportunidad, a través del arte, de integrar el material inconsciente y preconsciente en el trabajo creativo a través del yo (Bettelheim, 1964). El arte, en un proceso dialéctico único -porque refiere a las experiencias personales más profundas hechas universales a través del esfuerzo perceptivo y formal- puede considerarse como una de las fuerzas más importantes que unen a las personas sin vaciarlas de lo único e individual que cada una posee:

[El arte] permite compartir con otros aquello que todos consideran más elevado, algo que les eleva por encima de la experiencia cotidiana hacia una visión más ampliada de sí mismos. Y lo consigue haciendo que se sientan, más que nunca, distintivos y únicos. (Bettelheim, 1964, 58)

\section{Huellas, setenta años después}

La producción fotográfica, resultado del viaje realizado y que a continuación se muestra, está compuesta de varias series, y está organizada a partir del modo de referencia de la investigación basada en las artes (IBA), de la Universidad de Granada y coordinada por Ricardo Marín Viadel y Joaquín Roldán, emparentada de modo directo con A/R/Tography, un método de trabajo desarrollado por Rita Irwing y que combina la labor del artista, el docente y el investigador, de tal modo que permite la afluencia creativa y la autonomía de las imágenes como dadoras de sentido.

El modo de referencia muestra la autoría de la serie, el año, el título, el tipo de serie, y los datos de cada una de las fotografias (autoría, año y tipo de fotografía), reivindicando la necesidad de normalización de la cita y creación de imágenes. 

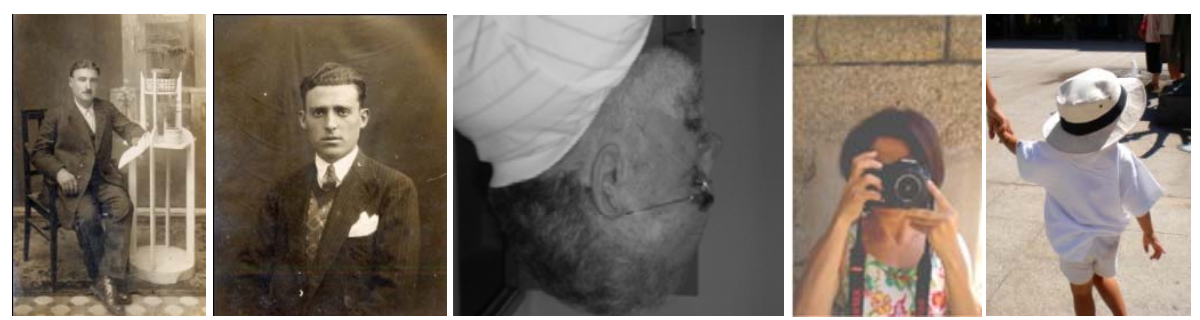

Figura 1. Autora (2007) Cinco generaciones. Serie descriptiva compuesta por cinco fotografías, de izquierda a derecha: Autoría desconocida (c.1930) Joaquín Cao, fotografía analógica; Autoría desconocida (c.1936)

Julio Cao Cao, fotografía analógica; Autora (2007) Agustín López Cao, fotografía digital; Federico López Gauli (2007) Marián López Fdez. Cao, fotografía digital; Federico López Gauli (2007) Bruno López Gauli, fotografía digital.
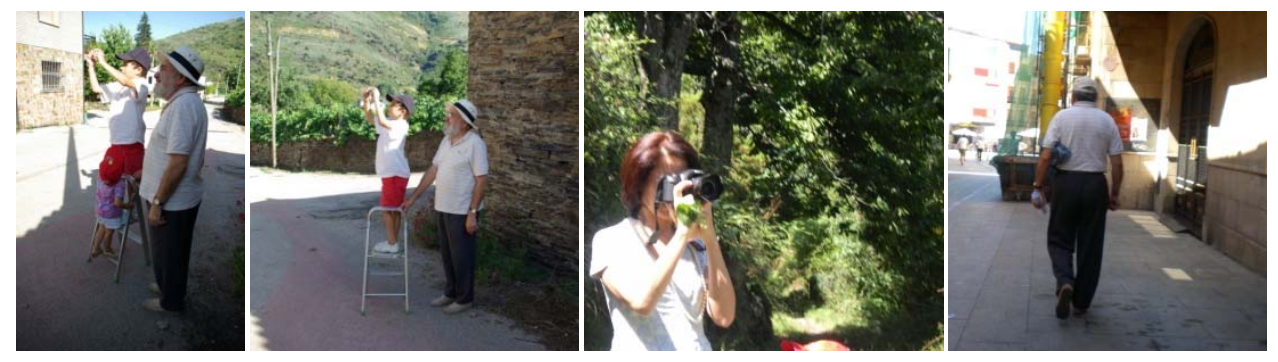

Figura 3. Autora (2007) Miradas I. Serie descriptiva compuesta por cuatro fotografías digitales, de izda a dcha: Autora (2007) s.t. 1; Autora (2007) s.t 2; Federico López Gauli (2007) s.t. ; Federico López Gauli (2007) s.t.
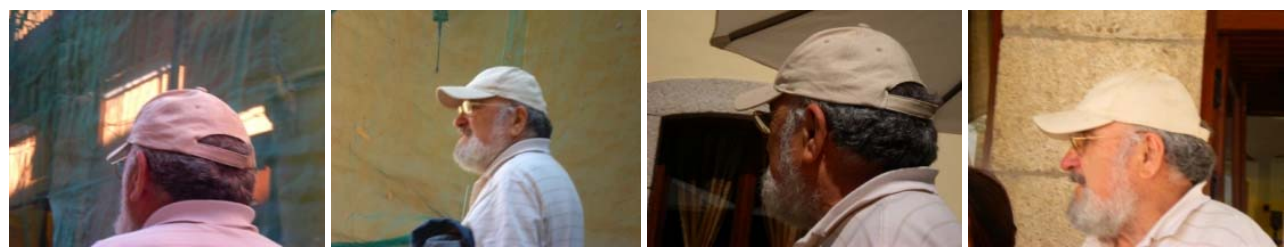

Figura 4. Autora (2007) Miradas II Serie descriptiva compuesta por cuatro fotografías digitales de la autora, de izda a dcha, (2007) s.t. 3; (2007) s.t 4; (2007) s.t. 5; (2007) s.t. 6. 


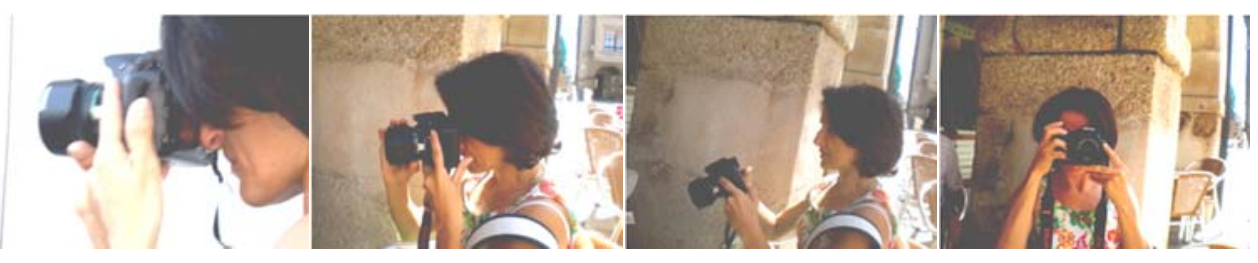

Figura 5. Autora (2007) Miradas III. Serie descriptiva compuesta por cuatro fotografías digitales, de izda a dcha: Federico López Gauli (2007) s.t.; Federico López Gauli (2007) s.t.; Federico López Gauli (2007)s.t. ; Federico López Gauli (2007) s.t.

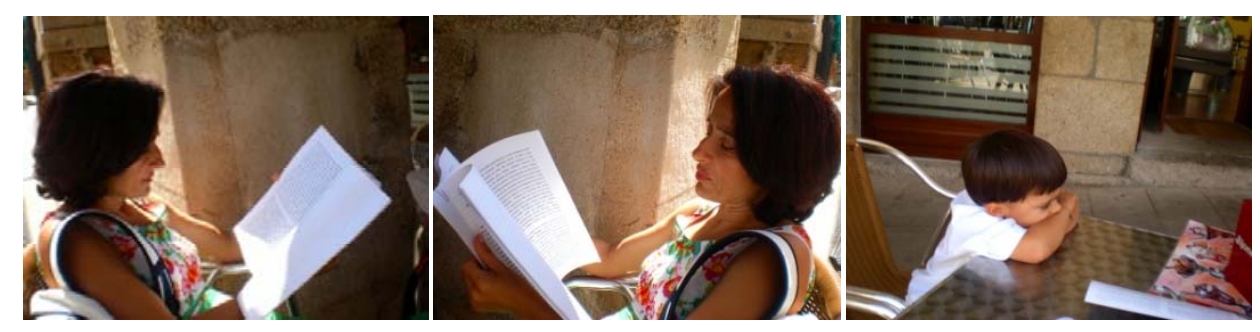

Figura 6. Autora (2007) Miradas IV. Serie descriptiva compuesta por tres fotografías digitales, de izda a dcha: Federico López Gauli (2007) texto I ; Federico López Gauli (2007) texto II.; Federico López Gauli (2007) Bruno se aburre.
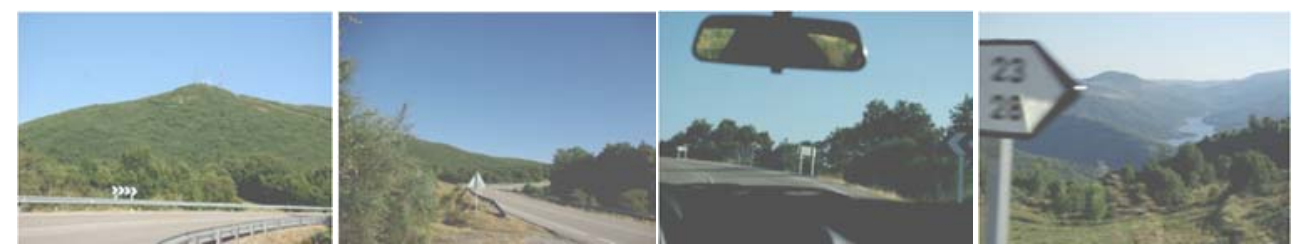

Figura 7: López Cao, Agustín y Autora (2007) Alto de Covelo I Serie comparativa compuesta por cuatro fotografías digitales, de izda a dcha: Autora (2007) s.t. 7; Autora (2007) s.t .8; Federico López Gauli (2007)

s.t. ; Federico López Gauli (2007) s.t.
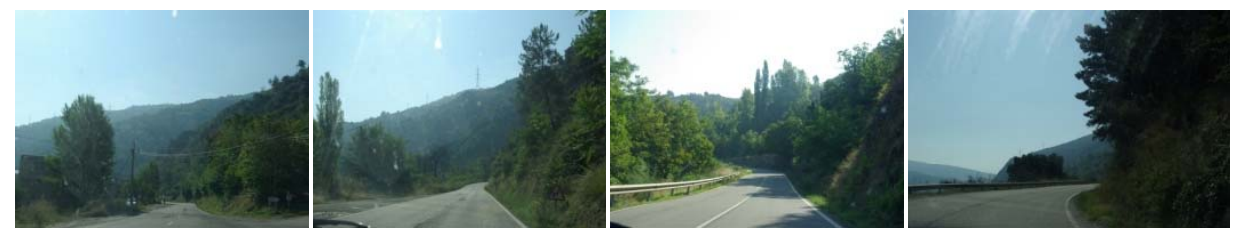

Figura 8: López Cao, Agustín y Autora (2007) La curva Serie descriptiva compuesta por cuatro fotografías digitales de la Autora, de izda a dcha: (2007) s.t. 9; Autora (2007) s.t 10; Autora (2007) s.t. 11; Autora (2007) s.t. 12. 

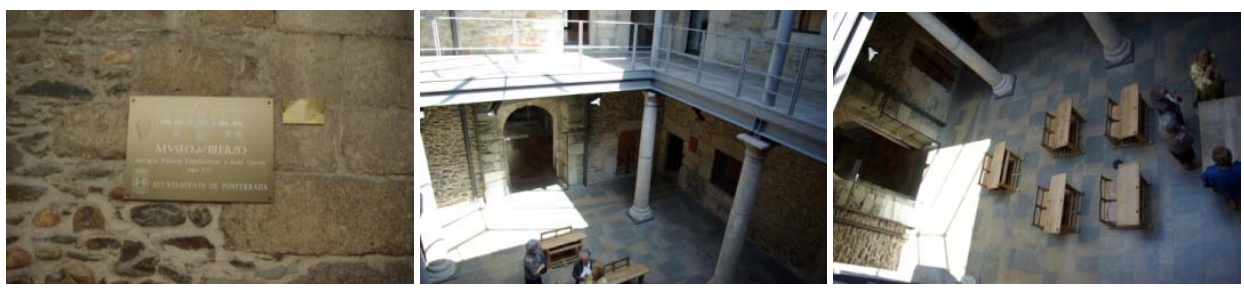

Figura 9: López Cao, Agustín/Autora (2007) El cajón Serie descriptiva compuesta por tres fotografías digitales de la Autora, de izda a dcha: (2007) s.t. 13; (2007) s.t . 14; (2007) s.t. 15 .
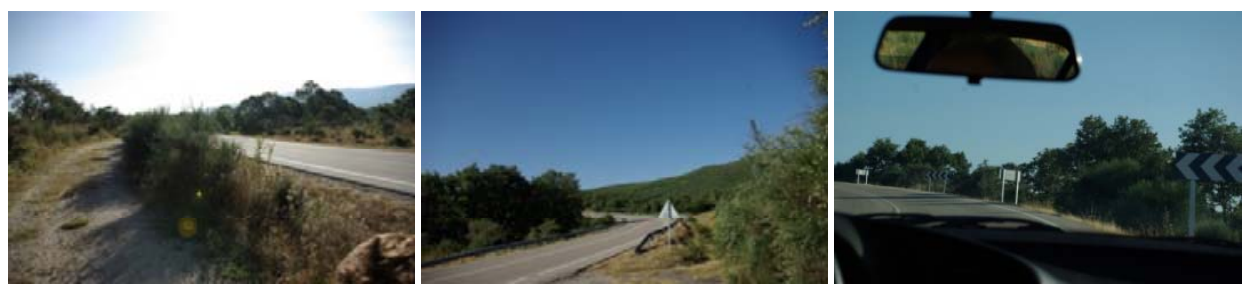

Figura 10: López Cao, Agustín, Autora (2007) Alto de Covelo Serie comparativa compuesta por tres fotografías digitales, de izda a dcha: Federico López Gauli (2007) s.t.; Autora (2007) s.t . 16; Autora (2007) s.t. 17.
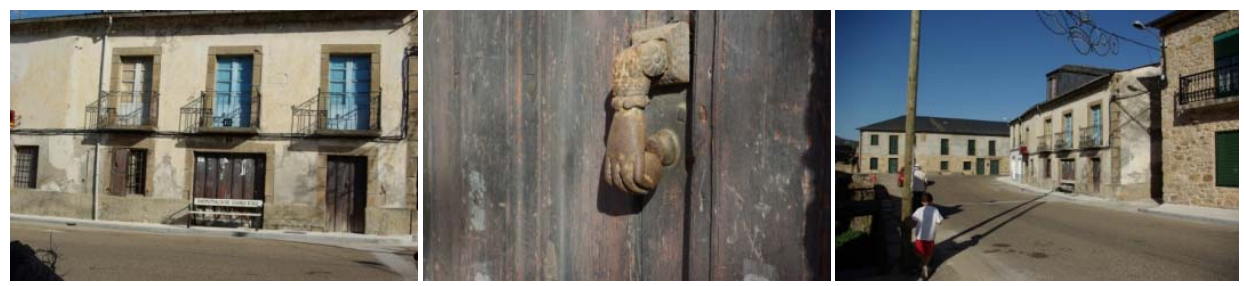

Figura 11: López Cao, Agustín/Autora (2007) A Rua Serie descriptiva compuesta por tres fotografías digitales de la autora, de izda a dcha: Autora (2007) s.t. 18; (2007) s.t 19; (2007) s.t. 20 .
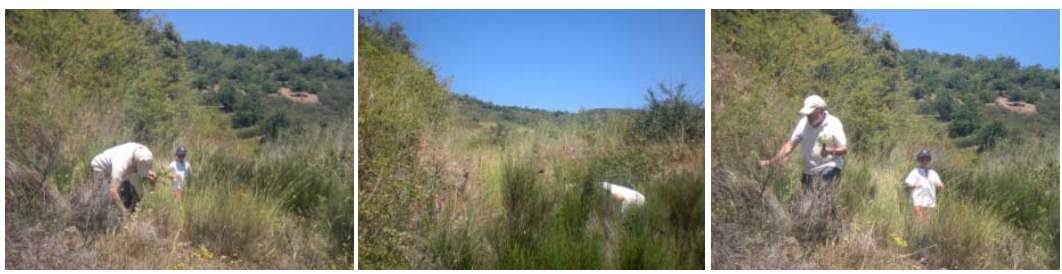

Figura 12: Autora (2007) Orégano Serie descriptiva compuesta por tres fotografías digitales, de la autora, de izda a dcha, (2007) s.t. 21; (2007) s.t . 22; (2007) s.t. 

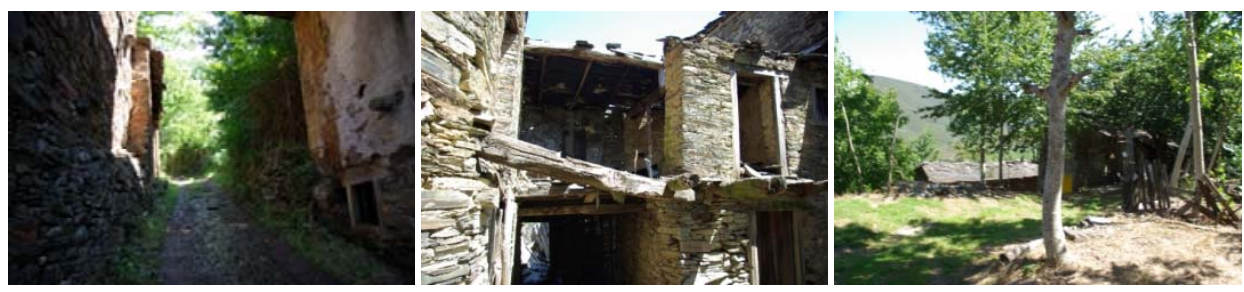

Figura 13: López Cao, Agustín/Autora (2007) Cereixido I Serie comparativa compuesta por tres fotografías digitales, de izda a dcha: Autora (2007) s.t. 24; Federico López Gauli (2007) s.t ; Autora (2007) s.t. 25.
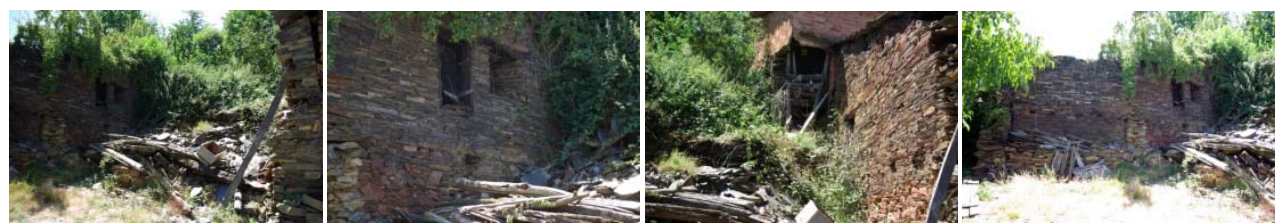

Figura 14: López Cao, Agustín/Autora (2007) Cereixido II Serie comparativa compuesta por cuatro fotografías digitales, de izda a dcha: Autora (2007) s.t. 26; Federico López Gauli (2007) s.t ; Autora (2007) s.t. 27; Autora (2007) s.t. 28.
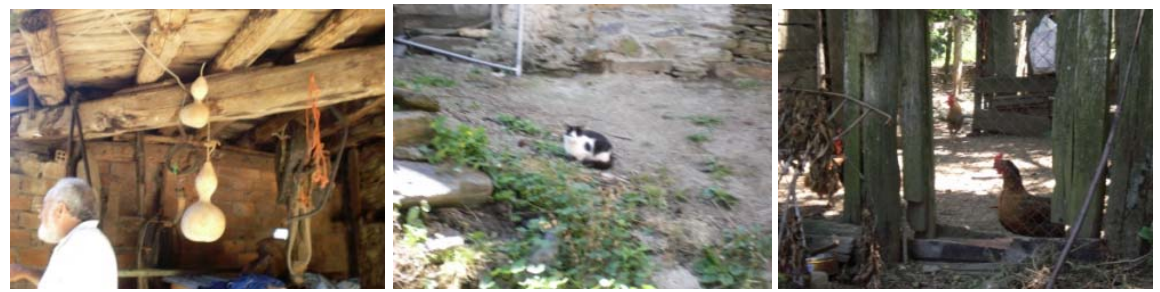

Figura 15: López Cao, Agustín/Autora (2007) Cereixido III Serie descriptiva compuesta por cuatro fotografías digitales, de izda a dcha: Federico López Gauli (2007) Abuelo; Federico López Gauli (2007) Gallina; Federico López Gauli (2007) Gato.
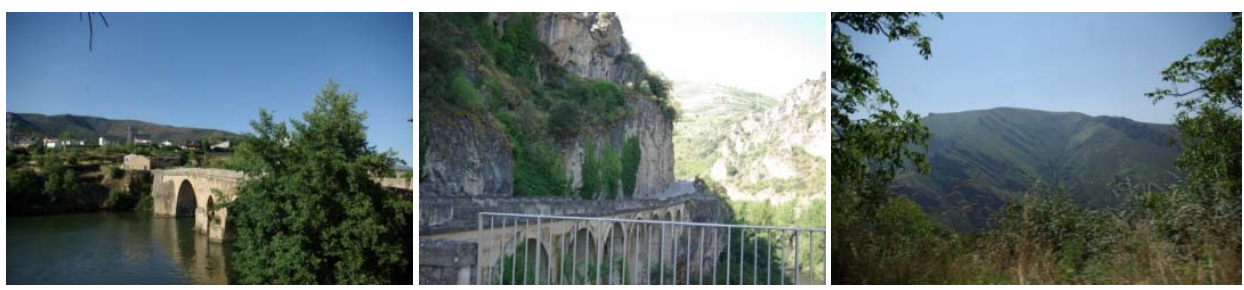

Figura 16: López Cao, Agustín/Autora (2007) Sil Serie comparativa compuesta por tres fotografías digitales, de izda a dcha: Autora (2007) s.t. 29; Federico López Gauli (2007) s.t ; Autora (2007) s.t. 30. 

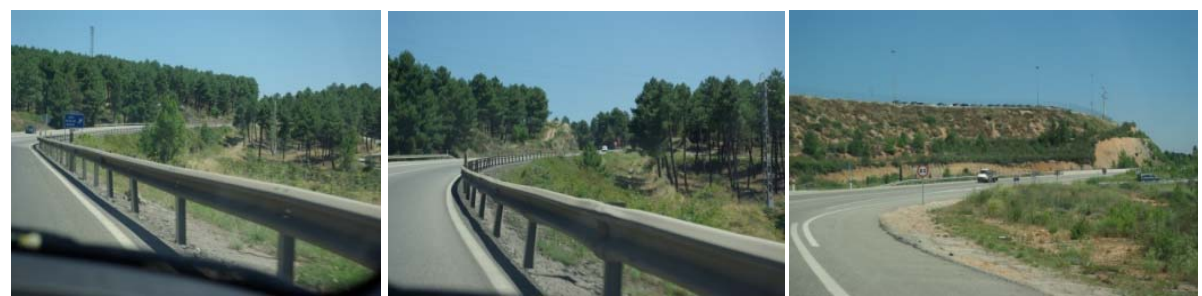

Figura 17: López Cao, Agustín/Autora (2007) Montearenas Serie descriptiva compuesta por tres fotografías digitales de la autora, de izda a dcha: (2007) s.t. 31; (2007) s.t. 32; Autora (2007) s.t. 33.

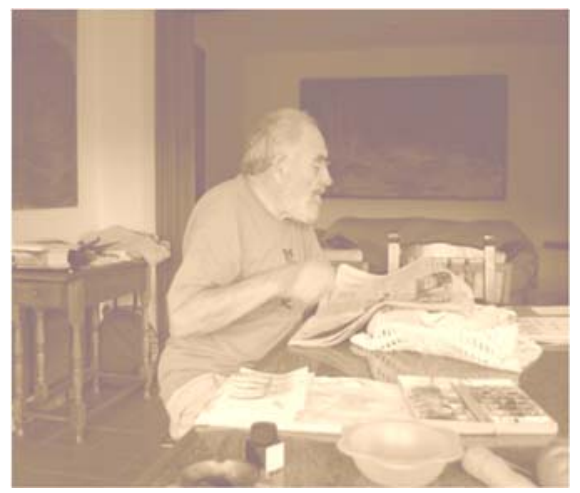

Figura 18: Autora (2007) Papá leyendo el periódico. Fotografía digital.

"y ni aun puedo tener el pequeño consuelo de saber el sitio fijo del poco espacio de terreno que su cuerpo ocupa".

(Joaquín Cao, Memorias... San Miguel de Outeiro, 5 de marzo de 1937)

\section{Referencias bibliográficas}

Arendt, H. (1995) De la Historia a la Acción. Barcelona, Paidós.

Bettelheim (1964) “Art: a personal vision". En Stoddard, George D.; Edman, Irwin; Bettelheim, Bruno (1964). Art. New York: The Museum of Modern Art, pp. 41-64.

Cao, J. (1937) Memorias de un padre cuyo hijo fue asesinado durante la revolución española. Inédito.

Christianson, S. A. (1992b) "Remembering emotional events: Potential mechanisms". In S.A. Christianson (ed.) The handbook of emotion and memory:Reseach and Therapy. Hillsdale, NJ: Lawrence Edbaum Associates Inc. 
Christianson, S. A.(1992a) "Emotional stress and eyewitness memory: A critical review". Psychological Bulletin, 112, 284-309.

Cobb, P., \& Bowers, J. (1999). "Cognitive and situated perspectives in theory and practice". Educational Reasearcher, 28, 2, 4-15

Cobley , P. (2001) Narrative. Londres: Routledge.

Collie, K., Backos, A., Malchiodi, C. A., \& Spiegel, D. (2006). “Art therapy for combatrelated PTSD: Recommendations for research and practice". Art Therapy: Journal of the American Art Therapy Association, 23(4), 157-164.

Francis, M. E. \& Pennebaker, J.W. (1992) "Putting stress into words. Writing about personal upheavals and health". American Journal of Health Promotion 6, 280-287.

Lange, A. (2000) "Interapy": the effects of a short protocolled treatment of posttraumatic stress and pathological grief through the Internet". Behavioural and Cognitive Psychotherapy, Volume 28, Issue 02, April 2000, pp 175-192.

López Fdez. Cao, M. (2011) Memoria, ausencia e identidad. Madrid, Eneida.

O'Kearney \& Perrott, 2006, "Trauma narratives in postraumatic stress disorder: A review". Journal of Traumatic Stress 19 (1), 81-93. Doi: 10.1002/ jts 20099.

Páez, Darío Campos, Miryam y Bilbao, M. Ángeles (2008) Del Trauma a la Felicidad: Pautas para la Intervención.- En Vázquez y hervás (eds.) Psicología positiva aplicada. Bilbao, españa: Editorial Desclée de Brouwer.

Pennebaker, J. W. y Beall, S. (1986) "Confronting a traumatic event: toward an understanding of inhibition and disease". Journal of Abnormal Psychology, 95, 274281.

Pennebaker, J.W. (1990). Opening Up: The Healing Powers of Confiding in Others. New York: William Morrow.

Rauch, S.L. and Shin, L.M. (1997) "Functional neuroimaging studies in posttraumatic stress disorder”. Ann. N.Y. Acad. Sci., 821: 83-98.

Reisberg \& P. Hertel (Eds.), Memory and emotion. New York: Oxford University Press

Sheehan, J. (1997) German History. Oxford Univeristy Press.

Stoddard, George D.; Edman, Irwin; Bettelheim, Bruno (1964). Art. New York: The Museum of Modern Art.

Van der Kolk \& Fisler, 1995) "Dissociation and fragmentary nature of traumatic memories: Onerview and exploratory study". Jounal of Traumatic Stress, 15, 255-258. 